\title{
A new integrated HPHT experimental apparatus to measure interfacial tension, swelling factor, and viscosity simultaneously
}

\author{
Andri Luthfi L. Hakim ${ }^{1}$ (D) Asep K. Permadi ${ }^{2}$ - Wisup Bae ${ }^{3}$. Won S. Ryoo ${ }^{4}$
}

Received: 13 September 2021 / Accepted: 20 January 2022 / Published online: 15 February 2022

(c) The Author(s) 2022

\begin{abstract}
An experimental apparatus has been designed to investigate interaction among $\mathrm{CO}_{2}$ injection parameters. It is an integratedclosed system of measurement kits that aimed to obtain interfacial tension, swelling factor, and viscosity data simultaneously. The apparatus had been successfully tested to measure properties of dead and live oils mixed with $\mathrm{CO}_{2}$ in high-pressure and high-temperature environment. An experimental study was completed using samples from real fields. Results showed consistency and coherency among the parameters that can be utilized to estimate the minimum miscibility pressure (MMP) graphically. The MMP is taken as the pressure at the intersection between two straight lines.
\end{abstract}

Keywords Viscosity $\cdot$ Interfacial tension $\cdot$ Swelling factor $\cdot$ MMP

\section{Introduction}

Oil field development can be carried out in up to three stages namely primary, secondary, and tertiary recovery. The third stage is also known as enhanced oil recovery (EOR). $\mathrm{CO}_{2}$ injection is one of the EOR methods applied widely. It has long been well known that the optimum $\mathrm{CO}_{2}$ flood depends on the miscibility condition. The miscibility condition between $\mathrm{CO}_{2}$ and the reservoir crude oil will determine how much oil will be recovered.

Miscibility is described as the ability of two or more substances to form a single homogeneous phase when mixed in all proportions. Miscibility is also defined as a physical condition between two or more liquids that allows them to be mixed in all proportions in the absence of a contact interface i.e. zero interfacial tension. If two liquid phases are formed

Asep K. Permadi

asepkpermadi@live.com

Bass Oil Sukananti Limited, Jakarta, Indonesia

2 Department of Petroleum Engineering, Institut Teknologi Bandung, Jalan Ganesa No. 10, Bandung 40132, Indonesia

3 Department of Energy and Mineral Resources Engineering, Sejong University, Seoul, South Korea

4 Department of Chemical Engineering, Hongik University, Seoul, South Korea after the addition of one liquid, then the liquids are considered immiscible (Stalkup 1978).

The highest oil recovery can be achieved if the $\mathrm{CO}_{2}$ flood happens in a miscible condition. To achieve that condition, the injection pressure must be greater than a certain minimum. This minimum pressure is hereafter defined as the minimum miscibility pressure, abbreviated MMP (Stalkup 1978). Another author defines MMP as the lowest pressure at which the $\mathrm{CO}_{2}$ injection fluid can develop miscibility with reservoir crude oil at reservoir temperature (Mungan 1981). Regardless of miscible or immiscible, it is believed that $\mathrm{CO}_{2}$ injection may contribute to increasing oil recovery because of viscosity reduction, crude oil swelling, interfacial tension lowering effects, and the internal solution of $\mathrm{CO}_{2}$ gas drive.

\section{Brief review on MMP determination methods}

The MMP is very important for making the right $\mathrm{CO}_{2}$ injection design. Many measurement methods have been proposed in the literature. They are divided into two approaches, computational (non-experimental) and laboratory (experimental). In this section, we will briefly review and discuss non-experimental approaches to determining MMP such as correlation, equation of state (EOS), and slim tube simulation, as well as revisit some understanding of experimental approaches. 


\section{Non-experimental MMP determination}

Computational methods for MMP estimation have been developed over the years based on the EOS either analytically or numerically. Several authors have proposed correlations to estimate the MMP such as Metcalfe (1982) and Orr and Silva (1987) who proposed a correlation of MMP as a function of temperature.

Assuming the correct EOS is based on a characterization of the liquid phase behavior, the MMP can be numerically calculated. The EOS reliability depends on the quality of the data used and the composition of the oil. Wang and Peck (2000) demonstrated that among the various available approaches, the compositional simulation can predict the MMP very consistently while following the slim tube test results. The inclusion of numerical dispersion in the simulation helps in characterizing the proper fluid phase behavior. Zick (1986), Stalkup (1987), and Stalkup et al. (1990) show that the numerical computation and slim tube simulation provide an excellent comparison to the experimental data. Slim tube simulation is cheaper and faster than an actual experiment but, to obtain a reliable estimation of the MMP results, the oil, and gas-phase behavior must be well explained in the EOS.

Enick et al. (1989) explain that the correlation for predicting the MMP should be a function of thermodynamic properties, or physics that affect the fluid miscibility and should be related to multiple contact miscibility processes. However, correlation reliability is usually limited to the range of composition used when the correlation was developed. None of these correlations provide adequate emphasis on oil composition and properties and all fail to predict the MMP accurately for different types of oil (Alomair et al. 2015).

\section{Correlation and EOS}

Several correlations were used to evaluate the MMP determination as a function of temperature and oil composition. Many authors have proposed correlations to determine the MMP, but only 7 correlations used in this investigation are those proposed by Yellig and Metcalfe (1980), Orr and Jensen (1984), Glaso (1985), Alston et al. (1985), Emera and Sarma (2006), Zhang et al. (2004), and Yuan et al. (2004). Peng-Robinson EOS was used for comparison. Table 1 shows crude sample used in this calculation and the result is shown in Fig. 1.

Zhang et al.'s correlation was used as a basis to understand the effect of crude components on the MMP. They published the empirical correlation in the following form,

$\mathrm{MMP}=\mathrm{a}[\ln (1.8 T+32)]^{\mathrm{b}}\left[\ln \left(\mathrm{Mc}_{7+}\right)\right]^{\mathrm{c}}\left(1+\frac{x_{\mathrm{VOL}}}{x_{\mathrm{MED}}^{\prime}}\right)^{\mathrm{d}}$
Table 1 Sample composition for correlations

\begin{tabular}{lll}
\hline Component & & Mole (\%) \\
\hline Hydrogen sulfide & $\mathrm{H}_{2} \mathrm{~S}$ & 0.0000 \\
Carbon dioxide & $\mathrm{CO}_{2}$ & 2.2447 \\
Nitrogen & $\mathrm{N}_{2}$ & 0.0460 \\
Methane & $\mathrm{C}_{1}$ & 2.1834 \\
Ethane & $\mathrm{C}_{2}$ & 1.0952 \\
Propane & $\mathrm{C}_{3}$ & 9.0753 \\
Iso-butane & $\mathrm{iC}_{4}$ & 4.0723 \\
n-Butane & $\mathrm{nC}_{4}$ & 5.7455 \\
Iso-pentane & $\mathrm{iC}_{5}$ & 4.8194 \\
n-Pentane & $\mathrm{nC}_{5}$ & 3.8891 \\
Hexane & $\mathrm{C}_{6}$ & 9.3083 \\
Heptane plus & $\mathrm{C}_{7+}$ & 57.5208 \\
& & 100.0000
\end{tabular}

Properties of heptane plus

Molecular Weight

128.86

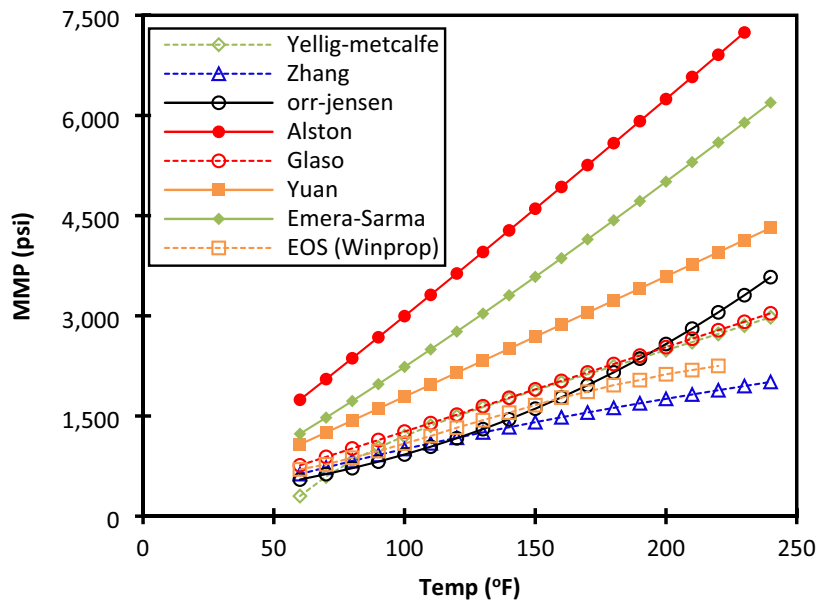

Fig. 1 MMP versus T based on various empirical correlations

where $\mathrm{a}=8.3397 \times 10^{-5}, \mathrm{~b}=3.9774, \mathrm{c}=3.3179$, and $\mathrm{d}=1.7461 \times 10^{-1}$. Fifteen crude samples with different compositions were used as can be seen in Table 2 . The results were compared to each other as shown in Figs. 2 and 3. The two figures indicate that it is easier to understand the prediction of MMP as a function of MW $\mathrm{C}_{7+}$ rather than intermediate component. The MMP will increase when the molecular weight increases.

\section{Slim tube simulation}

The evaluation of MMP determination was also done for the numerical simulation method. The sample shown in Table 1 was used in the simulation while the constructed 
Table 2 Sample properties for evaluating the effect of crude components on the MMP

\begin{tabular}{llll}
\hline Crude sample & MW C $_{7+}$ & API & $\mathrm{C}_{2}-\mathrm{C}_{6}$ \\
\hline X1 & 196 & 35 & 35 \\
A5 & 136 & 36 & 17 \\
A7 & 145 & 41 & 14 \\
A9 & 143 & 38 & 14 \\
A10 & 175 & 36 & 15 \\
A11 & 136 & 40 & 11 \\
A15 & 171 & 35 & 17 \\
A20 & 143 & 39 & 11 \\
A21 & 143 & 48 & 21 \\
K1 & 190 & 37 & 46 \\
TRM3 & 129 & 27 & 41 \\
TGI1 & 207 & 29 & 35 \\
RDG & 216 & 42 & 23 \\
TAF & 280 & 26 & 37 \\
BRF & 209 & 31 & 36 \\
\hline
\end{tabular}

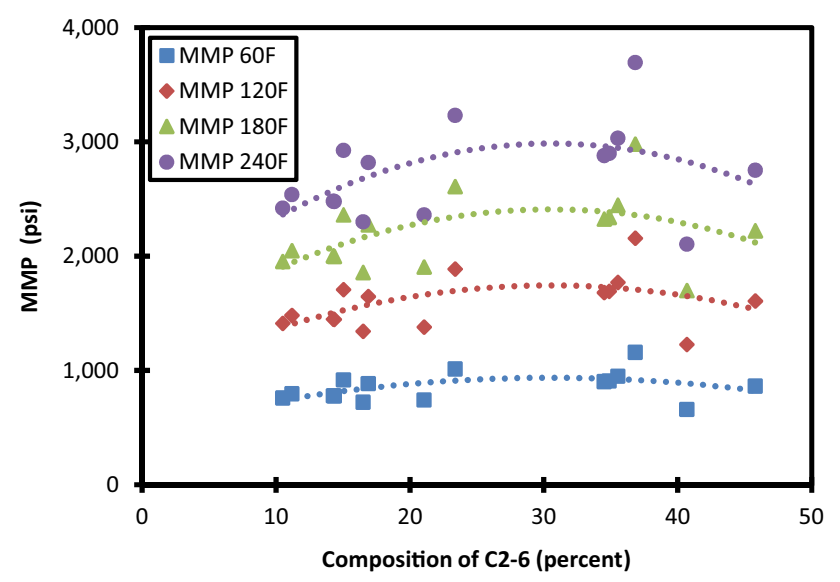

Fig. 2 MMP as a function of intermediate component

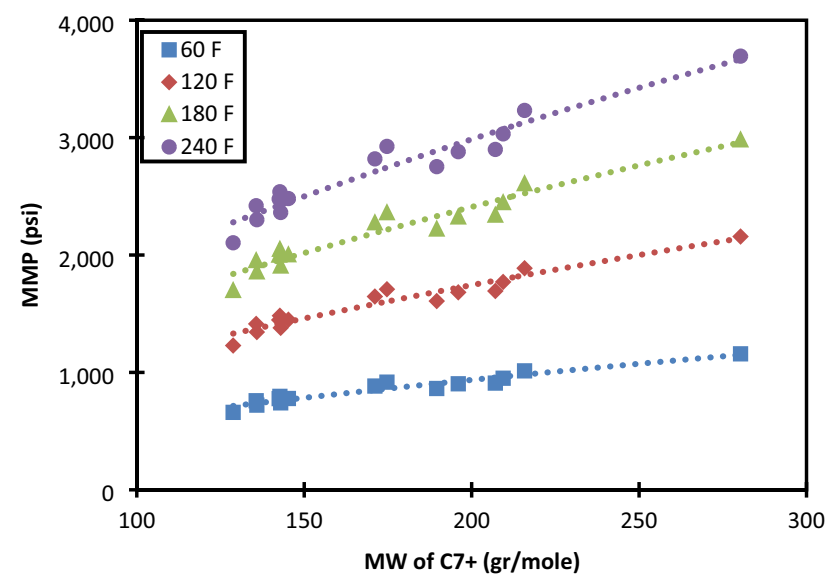

Fig. $3 \mathrm{MMP}$ as a function of $\mathrm{C}_{7+}$ molecular weight
Table 3 Slim tube simulation model properties

\begin{tabular}{lll}
\hline Properties & \multicolumn{2}{l}{ Value } \\
\cline { 2 - 3 } Length & 100 & $\mathrm{ft}$ \\
\hline Porosity & 35 & $\%$ \\
Permeability & 300 & $\mathrm{mD}$ \\
Inside diameter & 0.02 & $\mathrm{ft}$ \\
\hline
\end{tabular}

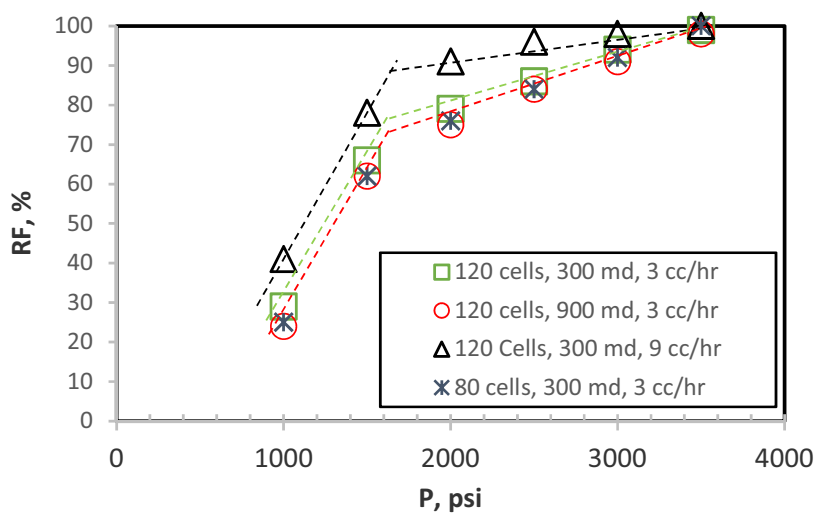

Fig. 4 Sensitivity of slim tube parameters on recovery

model properties are shown in Table 3. The result of these runs is shown in Fig. 4.

The results in Fig. 4 indicate that the MMP determined by simulations is dependent on the slim tube model properties. In addition to the coil length, the results are also strongly affected by experiment parameters such as injection rate.

\section{Experimental MMP determination}

There are several experimental methods currently available to determine the MMP including slim tube experiment, swelling test, rising bubble apparatus, and the interfacial tension method. The slim tube experiment method is believed as the only way that gives the most satisfactory result. The slim tube method was proposed by Yellig and Metcalfe in 1980.

The swelling test, originally proposed by Hand and Pinczewski in 1990, is a method used to determine the amount of additional oil volume when injected with $\mathrm{CO}_{2}$. This method was later developed to determine the MMP by some authors including Tsau et al. (2010) and Abdurrahman et al. (2015). The MMP is determined at the intersection between the extraction condensation and the extraction stages. However, according to some authors, the intersection will not occur if the extraction zone or extraction line is not formed, which happens when the oil sample does not contain heavy components. Nevertheless, among the advantages of this method is that it will provide a possibility to observe scale deposition 
and crude oil precipitation when the miscible condition is achieved.

The rising bubble apparatus is designed as an alternative way that can provide results as fast and reliable as given by the slim tube experiment. It was first proposed by Christiansen and Haines in 1987. Gas bubbles are injected into the glass tube from a hollow needle at the bottom of the sight gauge. The whole rising process of the bubbles and their shape and behavior are observed and photographed with a camera to estimate the MMP.

The MMP measurement method can also be approximated by utilizing the interfacial tension data. By applying the Vanishing Interfacial Tension (IFT) technique (Rao 1997), the interfacial tension data measured at several pressure steps are analyzed by plotting the IFT value against the pressure, then the correlation is extrapolated to IFT zero which is then considered as the MMP. During $\mathrm{CO}_{2}$ flooding, several processes occur simultaneously including vaporization, swelling, viscosity, and interfacial tension reduction. This simultaneous process makes it difficult to isolate the effect of each process on MMP (Rosman and Zana 1977). The difficulty also increases because it is known that the viscosity reduction is one of the major mechanisms that occur during the process of miscible and immiscible $\mathrm{CO}_{2}$, as shown by the results of laboratory experiments conducted by Holm (1987), and Sugiharjo and Purnomo (2009). The higher viscosity oils deliver a greater viscosity reduction for each saturation pressure, as can be seen in Fig. 5.

There is no standard method available in the literature on what would be the correct method in determining the MMP. The slim tube method has been traditionally used to estimate the MMP because it models the interaction of flow in porous media and phase behavior of crude oil (Ekundayo and Ghedan 2013; Flock and Nouar 1984). Although the slim tube method is often considered as the standard way to measure the MMP, it is generally time-consuming and expensive. It usually takes weeks to perform a set of injections.

\section{Development of new apparatus}

The fact that there is no standard method to determine the MMP has motivated the development of a new integrated but more reliable way of MMP estimation. The basic idea is develop an equipment that capable to measure the MMPdetermining parameters simultaneously in order to ensure the coherence of the data obtained. The implementation is to combine several measurement kits in a closed system so that measurements can be carried out for samples that have the same and consistent composition. The sets of coherent data will eventually improve the reliability of the estimated MMP. In this case, the new method is expected to answer the problem of MMP determination uncertainties.

The new apparatus was then built by integrating and installing measurement equipment including a swelling factor measurement cell, a viscosity measurement probe, and an interfacial tension measurement cell. All the kits were placed within an air bath container and connected with each other so that they form a closed system. The apparatus was designed in such a way that it can also be used as a PVT cell to generate live oil samples through recombination process by applying a constant volume technique. The apparatus was also designed that it can be used to observe changes in behavior of crude properties while flooded by $\mathrm{CO}_{2}$. In

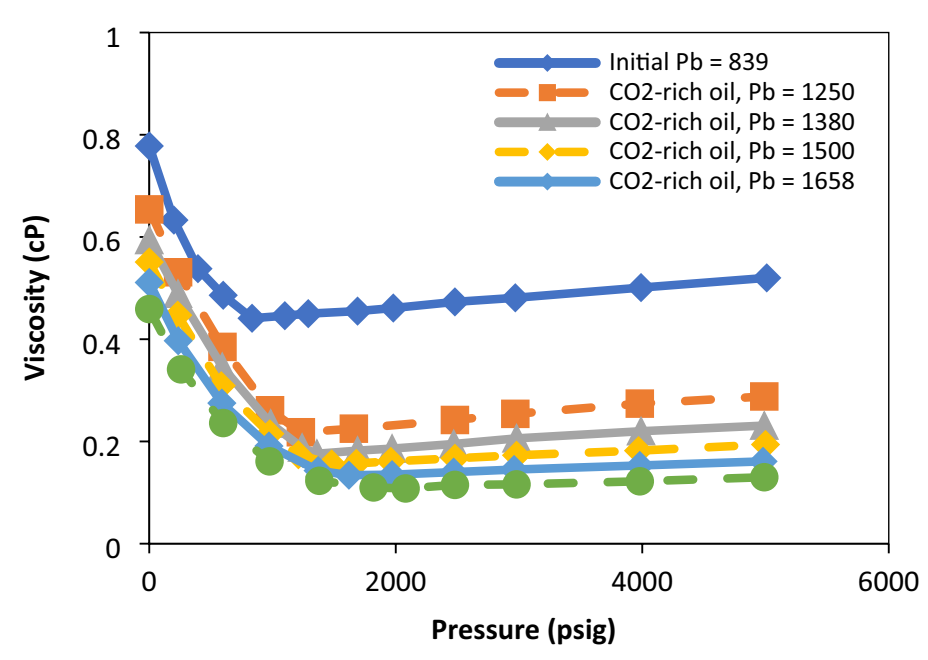

(a)

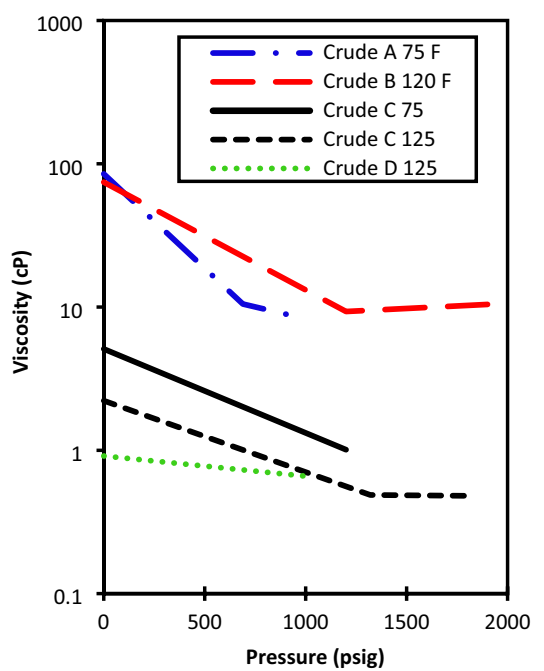

(b)

Fig. 5 Oil viscosities as a function pressure and amount of $\mathrm{CO}_{2}$ : a Sugiharjo and Purnomo (2009) and b Holm (1987) 
such case, the apparatus was designed as a multifunctional solution for a unique measurement method. This includes the capability of synthetic live oil generation, swelling test/ viewing cell, high-pressure and high-temperature viscosity measurement, and interfacial tension/pendant drop measurement. All of the measurements are done simultaneously and continuously. It is then expected that by acquiring the parameters simultaneously, consistency can be guaranteed and the MMP can be estimated with high confidence. The diagram and actual picture of the developed apparatus are shown in Figs. 6 and 7, respectively.

\section{Apparatus test and experiment procedure}

Figure 8 shows the results of the initial apparatus test. It was successfully tested to generate synthetic live oil in the PVT/ swelling cell and was successfully run until the working pressure and temperature reach $3600 \mathrm{psi}$ and $85^{\circ} \mathrm{C}$, respectively. It is capable of measuring viscosity, swelling factor, and interfacial tension simultaneously at high-pressure and high-temperature condition. It can also accommodate a fluid recombination process similar to a PVT cell which can be used for synthetic live oil generation.

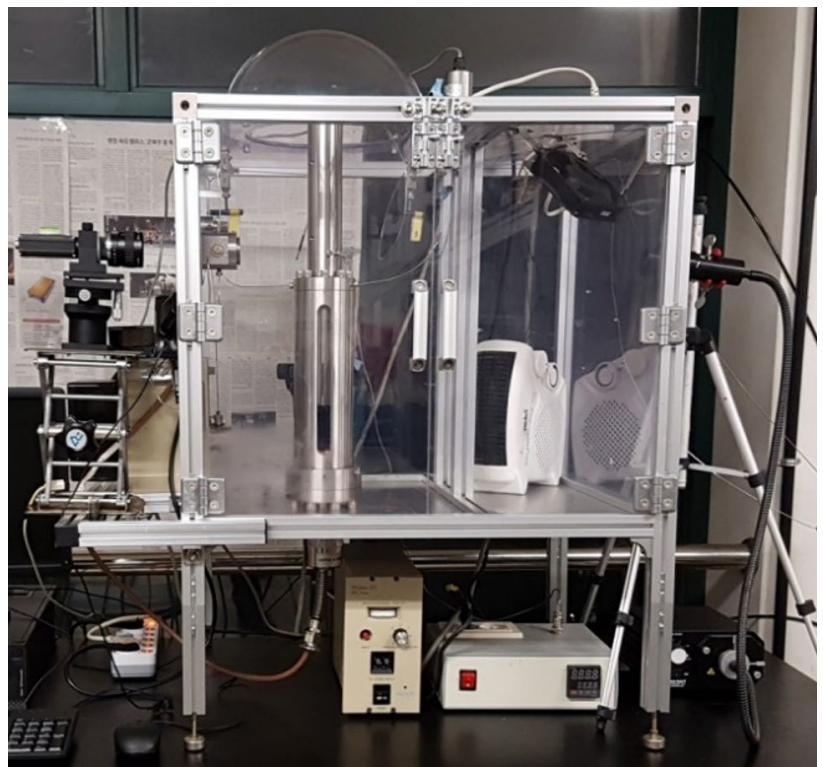

Fig. 7 New apparatus set-up in the laboratory

In addition, this apparatus can also be able to observe visually the miscibility phenomena to study the behavior of the three MMP-determining parameters during $\mathrm{CO} 2$ injection.

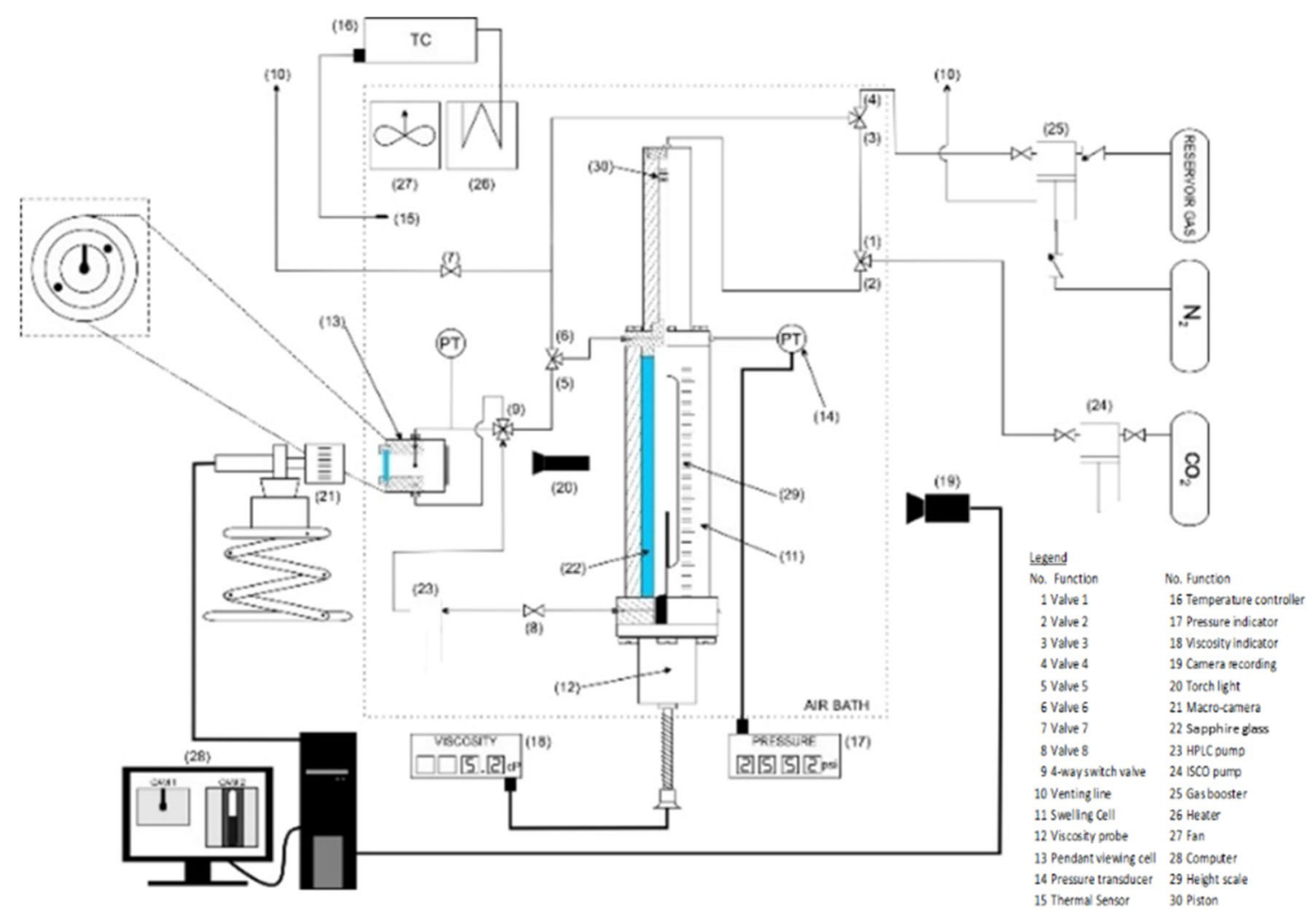

Fig. 6 New apparatus diagram 


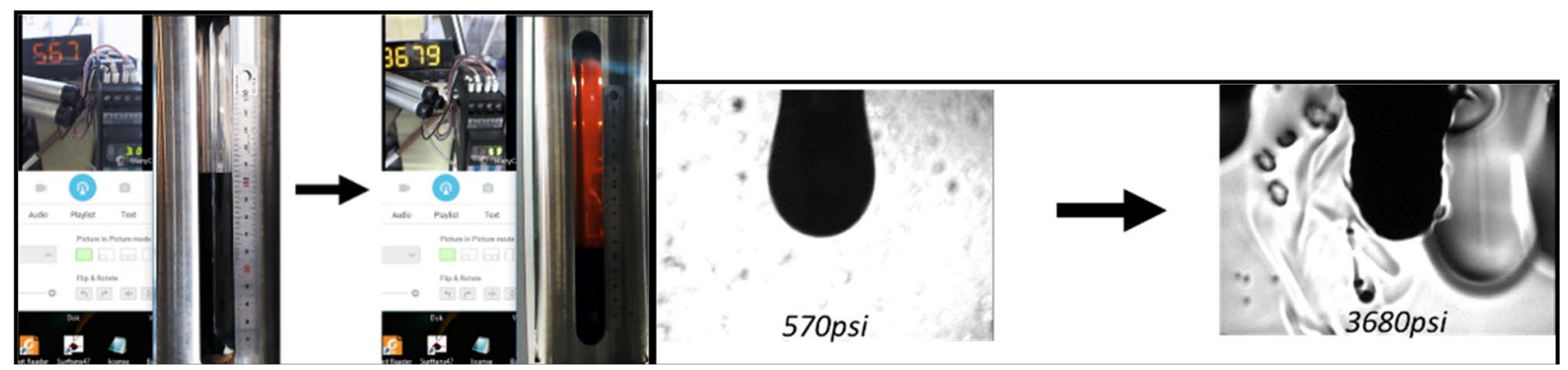

Fig. 8 Apparatus and data acquisition tests

Thus, the final objectives of the apparatus development that can be achieved are as follows:

1. capable to work in high-pressure and high-temperature environment up to $4,500 \mathrm{psi}$ and $100{ }^{\circ} \mathrm{C}$.

2. able to measure the three MMP-determining parameters of viscosity, swelling factor, and interfacial tension simultaneously by only one-step experiment.

3. allows validation for each measured parameter to ensure better estimation of MMP.

After the equipment passed the initial test, the experimental work continued. Two types of crude samples, paraffinic and aromatic oils, were used to test the capability of the apparatus. At this point, the main purposes of the laboratory work were to test the apparatus reliability and to determine the parameters that can be used to estimate the MMP. The parameters that were successfully measured include swelling factor, viscosity, and the interfacial tension.

The general working procedure of this apparatus for a specified temperature $T_{1}$ can be described as follows (see Fig. 6):

1. Place the sample of volume $\mathrm{V}_{1}$ in the swelling cell (11) at pressure $\mathrm{p}_{1}$ and temperature $\mathrm{T}_{1}$.

2. If the placed sample is dead oil then to make it synthetic live oil, inject the reservoir gas into the swelling cell (11) according to the gas-oil ratio (GOR) at the specified pressure and temperature.

3. Collect initial condition data consisting of initial viscosity $\mu_{1}$ measured by viscosity probe (12) by reading the viscosity indicator (18), initial pressure $\mathrm{p}_{1}$ by reading the pressure indicator (17), initial volume $\mathrm{V}_{1}$ measured through the scale attached to the outer surface of the swelling cell (11), and initial interfacial tension $\gamma_{1}$ measured through the pendant viewing cell (13).

4. When synthetic live oil sample is ready in the swelling cell (11), pump a certain amount of $\mathrm{CO}_{2}$ gas into the swelling cell (11) and circulate the system until it reaches equilibrium; the circulation helps reducing the aging time of $\mathrm{CO}_{2}$ to contact with the oil.

5. Do all measurements after the system reaches its balanced state. Then obtain $\mathrm{M}_{2}$ and $\mathrm{V}_{2}$ at $\mathrm{p}_{2}$ and $\mathrm{T}_{1}$.

6. Pump the sample into the pendant viewing cell (13). Record the value obtained from the pendant shape using a commercial interfacial tension calculator as $\gamma_{2}$.

7. Repeat Steps (4), (5), and (6) until reaching the desired pressure and temperature. To increase the pressure in the swelling cell (11), pump additional $\mathrm{CO}_{2}$ into the cell and/or use the piston (30).

The actual experiment using the above procedure was carried out using two sets of sample of aromatic oil Sample A1 and paraffinic oil Sample B1 as can be seen in Table 4 . The specific temperatures used in the experiments for the two samples are as follows:

Table 4 Live oil compositions for experiments

\begin{tabular}{|c|c|c|c|}
\hline \multicolumn{2}{|l|}{ Sample } & \multirow{2}{*}{$\begin{array}{l}\text { Paraffinic } \\
\text { sample B1 } \\
\text { Mol\% }\end{array}$} & \multirow{2}{*}{$\begin{array}{l}\text { Aromatic } \\
\text { sample } \\
\text { A1 } \\
\text { Mol\% }\end{array}$} \\
\hline Component & & & \\
\hline Hydrogen sulfide & $\mathrm{H}_{2} \mathrm{~S}$ & 0.00 & 0.00 \\
\hline Carbon dioxide & $\mathrm{CO}_{2}$ & 5.2027 & 0.3787 \\
\hline Nitrogen & $\mathrm{N}_{2}$ & 0.2163 & 0.4645 \\
\hline Methane & $\mathrm{C}_{1}$ & 15.1102 & 11.2789 \\
\hline Ethane & $\mathrm{C}_{2}$ & 2.16 & 0.1622 \\
\hline Propane & $\mathrm{C}_{3}$ & 10.1997 & 0.2503 \\
\hline Iso-butane & $\mathrm{i}-\mathrm{C}_{4}$ & 3.7506 & 0.1832 \\
\hline n-Butane & $\mathrm{n}-\mathrm{C}_{4}$ & 5.0606 & 0.4448 \\
\hline Iso-pentane & $\mathrm{i}-\mathrm{C}_{5}$ & 3.9205 & 2.3216 \\
\hline n-Pentane & $\mathrm{n}-\mathrm{C}_{5}$ & 3.1327 & 2.6256 \\
\hline Hexane & $\mathrm{C}_{6}$ & 7.2543 & 13.2666 \\
\hline \multirow[t]{2}{*}{ Heptane Plus } & $\mathrm{C}_{7+}$ & 43.9924 & 68.624 \\
\hline & & 100 & 100 \\
\hline \multicolumn{4}{|c|}{ Properties of heptane plus } \\
\hline Molecular weight & $:$ & 128.77 & 206.66 \\
\hline
\end{tabular}


1. Aromatic oil Sample A1 with $\mathrm{MWC}_{7+}=206.7$, pure $\mathrm{CO}_{2}$ injection case, temperatures of $104^{\circ} \mathrm{F}, 131^{\circ} \mathrm{F}$, and $158^{\circ} \mathrm{F}$.

2. Paraffinic oil Sample B1 with $\mathrm{MWC}_{7+}=128.7$, pure $\mathrm{CO}_{2}$ injection case, temperatures of $104^{\circ} \mathrm{F}, 131^{\circ} \mathrm{F}$, and $158^{\circ} \mathrm{F}$.

\section{Results and discussion}

Figure 9 shows the results from the measurements using aromatic oil Sample A1 at $104^{\circ}$ F. Figure 9a shows plots of the three parameters measured simultaneously with the

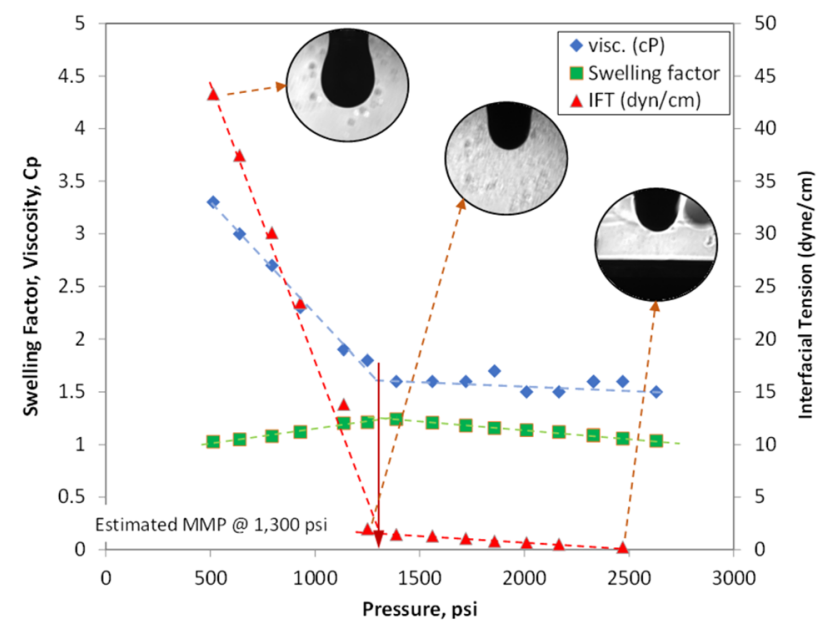

(a)

Fig. 9 Acquired data for Sample A1 at $104{ }^{\circ} \mathrm{F}$

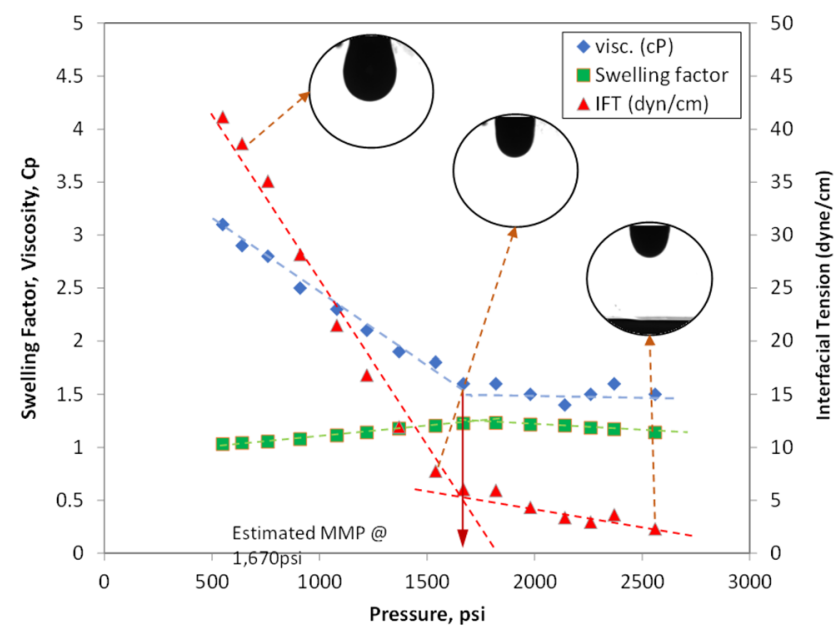

(a) corresponding pictures of pendant drops while Fig. 9b shows the corresponding changes in oil volume within the swelling cell. Since the measurement was done in a closed system, the composition of the sample must be the same in all measuring cells.

Figures 10 and 11 display the results of measurement for Sample A1 at $131^{\circ} \mathrm{F}$ and $158^{\circ} \mathrm{F}$, respectively. Similar behavior is observed for the swelling factor, the viscosity, and the interfacial tension curves. In this case, they always consist of two slopes with their breakpoints occur almost at the same pressure. The viscosity and the interfacial tension decrease steeply with the increasing pressure before the breakpoint while the swelling factor increases consistently before the breakpoint. This phenomenon indicates a unique change in oil properties while the oil is injected by $\mathrm{CO}_{2}$ i.e. where the

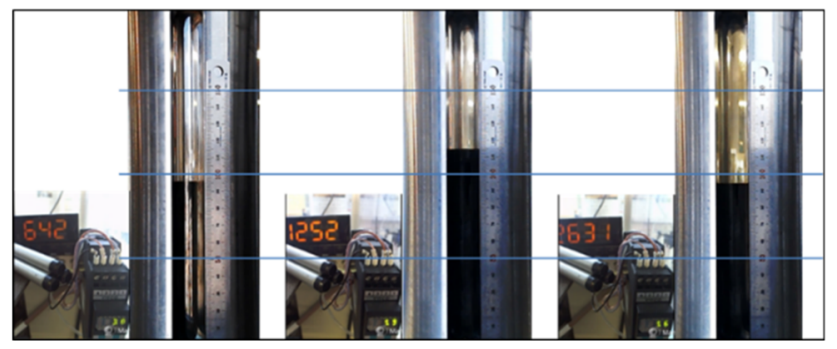

(b)

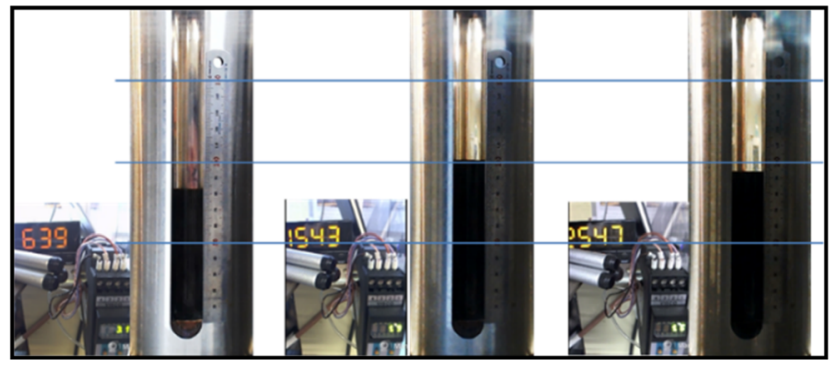

(b)

Fig. 10 Acquired data for Sample A1 at $131^{\circ} \mathrm{F}$ 


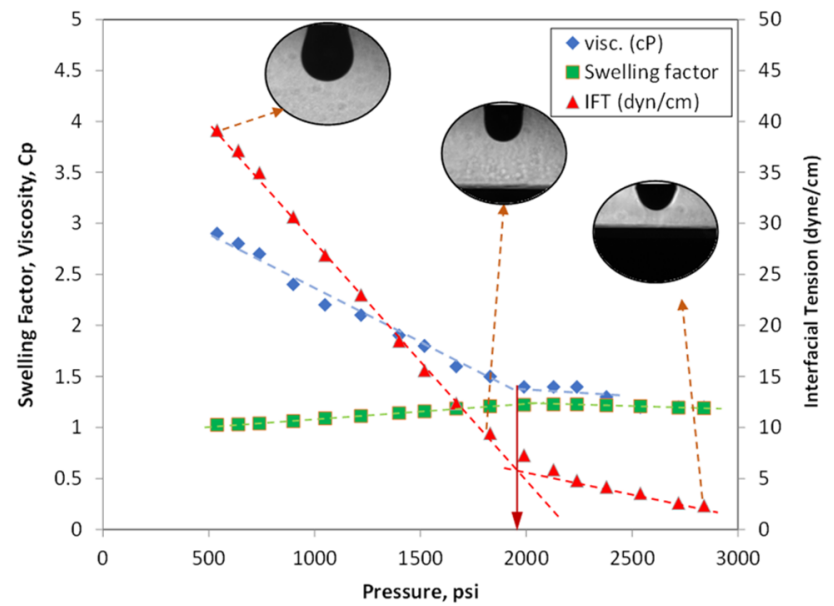

(a)

Fig. 11 Acquired data for Sample A1 at $158^{\circ} \mathrm{F}$

viscosity and the interfacial tension decrease significantly at the first slope while the swelling factor increases to its maximum value at the breakpoint. Further evaluation of this behavior allows us to conclude that the consistent occurrence of the breakpoint resulted in this experiment may be useful as a reference to determine the mixed fluid properties and behavior caused by $\mathrm{CO}_{2}$ injection.

Figures 10 and 11 also demonstrate consistent results with those of Fig. 9. The plots of the swelling factor, the viscosity, and the interfacial tension show similar curve shapes and behavior. If a line parallel to the y-axis is drawn down to the $\mathrm{x}$-axis, the line will intersect precisely at the intersection points of each of these curves. Further analysis revealed that the points clearly occur at different pressure for different temperature. In this case, the higher the temperature, the higher the pressure at which the points occur.

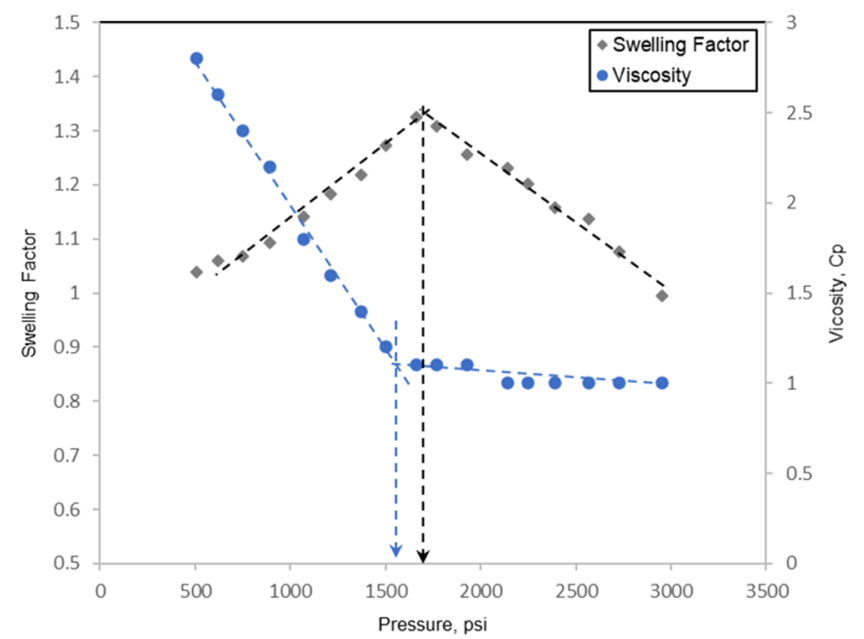

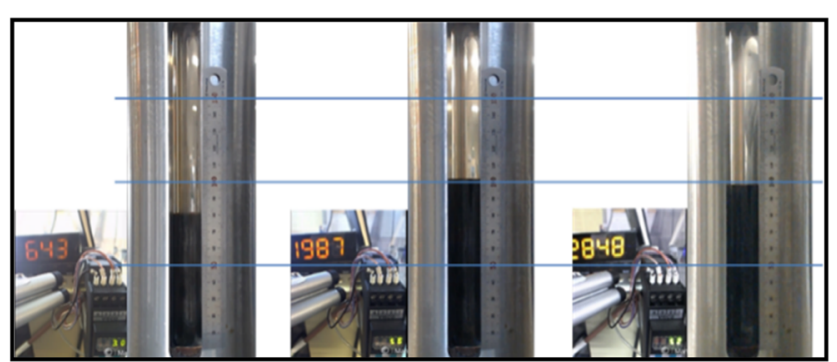

(b)
Further experiments have been carried out to ensure that the results obtained from this apparatus are consistent with other methods that have been proven to be accepted as a method to analyze the behavior of oil when injected with $\mathrm{CO}_{2}$, the chosen method is swelling factor. Sample A1 was chosen again to measure its parameters, only to test its consistency, a solvent was added to see the effect of changes in composition on the measurement value. Figure 12 shows that the results of the individual Viscosity and IFT measurements are consistent with the swelling factor experimental results.

Consistency checks were also carried out by comparing the experimental results with the Slimtube 1D simulation results using the same parameters (pressure and temperature), it was found that the breakpoint between Slimtube 1D, with Viscosity, IFT, and SF devices occurred at almost

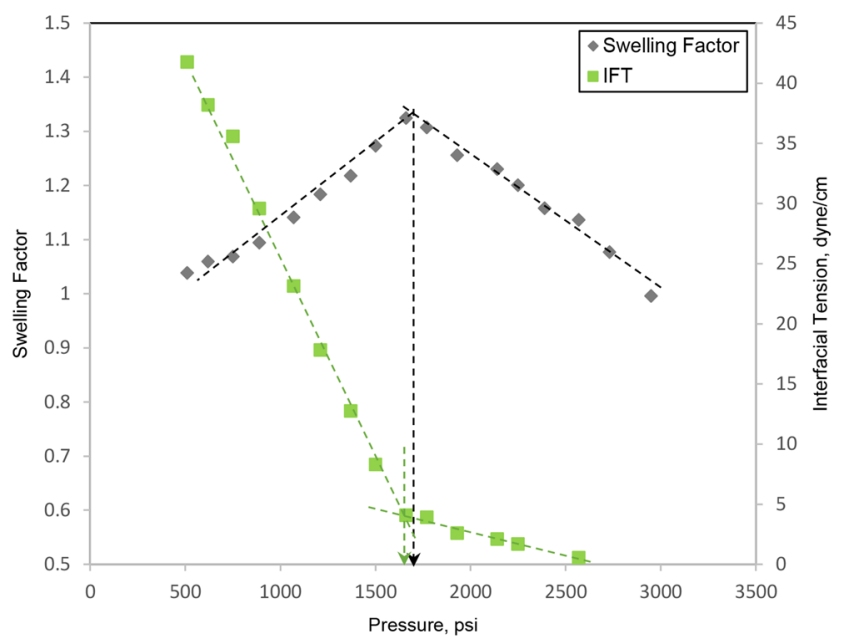

Fig. 12 Measurement results of vicosity and IFT (A1 plus solvent) versus Swelling Factor at $131{ }^{\circ} \mathrm{F}$ 
the same pressure (Fig. 13). Meanwhile, the breakpoints will be considered as a reference in all experiments to determine the change in fluid characteristics caused by $\mathrm{CO}_{2}$ injection. Figures 14, 15, 16, and 17 show the results of the experiment using Sample B1 which composed of paraffinic oil.

Figure 14 shows the experiment results of Sample B1 at $104{ }^{\circ} \mathrm{F}$. Figure $14 \mathrm{a}$ shows no viscosity data since the pour point of Sample B1 is $98^{\circ} \mathrm{F}$ which is slightly lower than the working temperature. At this point, the waxes became a crust at the vibrating rod of the viscosity probe causing an error in viscosity reading. Figure 15 proved that paraffin precipitation has occurred which likely causes the error reading. It was also found that it sometimes plugged the filter in the circulation pump. The precipitation also occurred even after the temperature was increased to above the pour point. The experiment became worst as the wax deposit could not be dissolved and eventually became crusted after the experiment was finished and the $\mathrm{CO}_{2}$ was released through the bleed-off line.

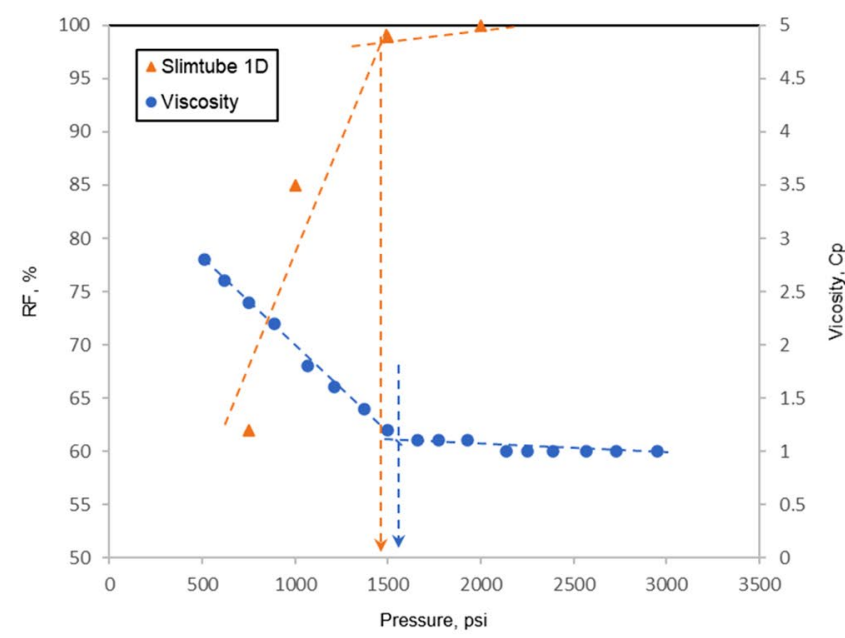

Paraffin precipitation has rarely been addressed in the literature although some authors have reported that precipitation was observed when $\mathrm{CO}_{2}$ was injected into an asphaltic oil. Therefore, this phenomenon has given a new insight that the precipitation also occurred in paraffinic oil that may result in serious problems during $\mathrm{CO}_{2}$ injection. The experiment was then conducted for higher temperatures to investigate the effect of temperature on paraffinic oil precipitation.

Figures 16 , the measurement at $131^{\circ} \mathrm{F}$, show a quite interesting result. The interfacial tension curve shows unfavorable way of interpretation since it does not look quite consistent with the other two curves, i.e. the swelling factor and the viscosity curves. This inconsistency indicates that the temperature strongly affected the interfacial tension readings. The wax spots at the glass have disturbed the measurement of the pendant. It can be seen in the figure that the pendant has an imperfect shape. In this specific experiment, the swelling factor and the viscosity curves have the intersection point at the same pressure while the interfacial tension curve has the intersection point at a slightly higher pressure.

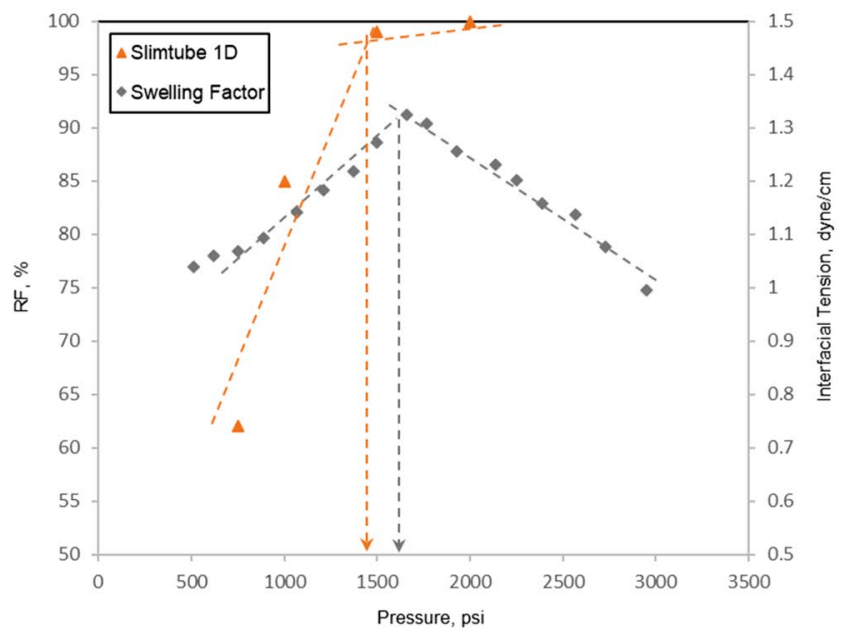

Fig. 13 Viscosity, IFT, and SF of modified A1 sample compared with 1D Slimtube at $131^{\circ} \mathrm{F}$ 

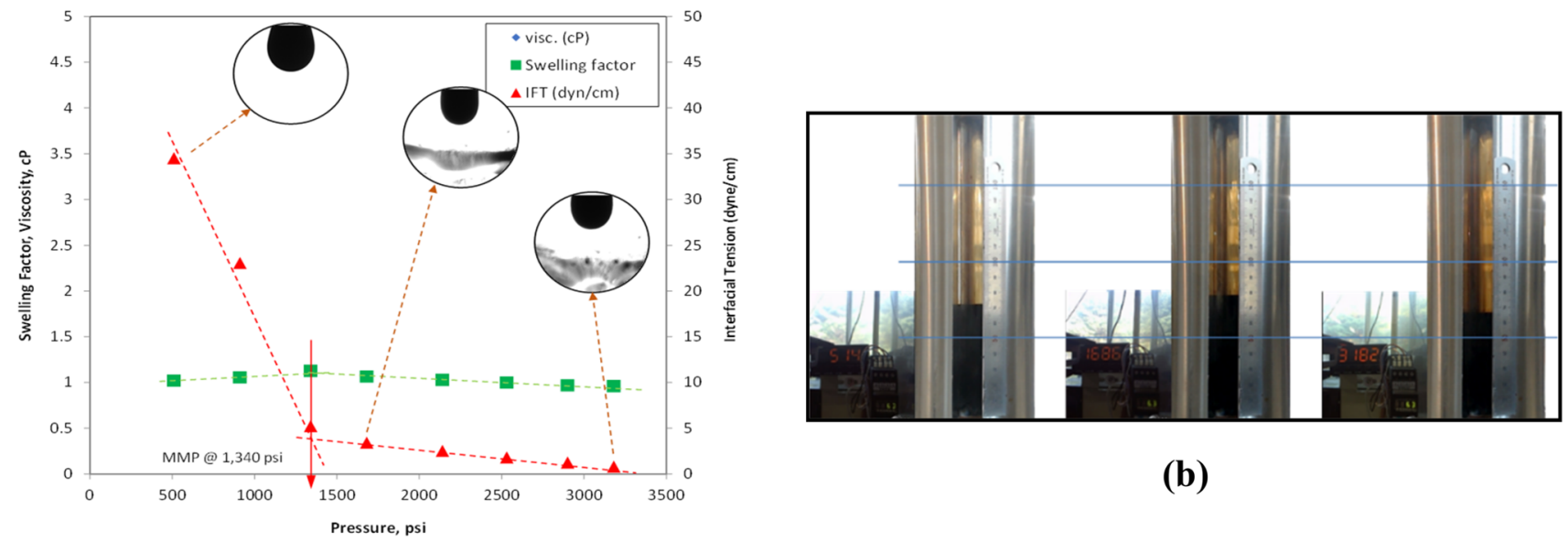

(b)

(a)

Fig. 14 Acquired data for Sample B1 at $104{ }^{\circ} \mathrm{F}$

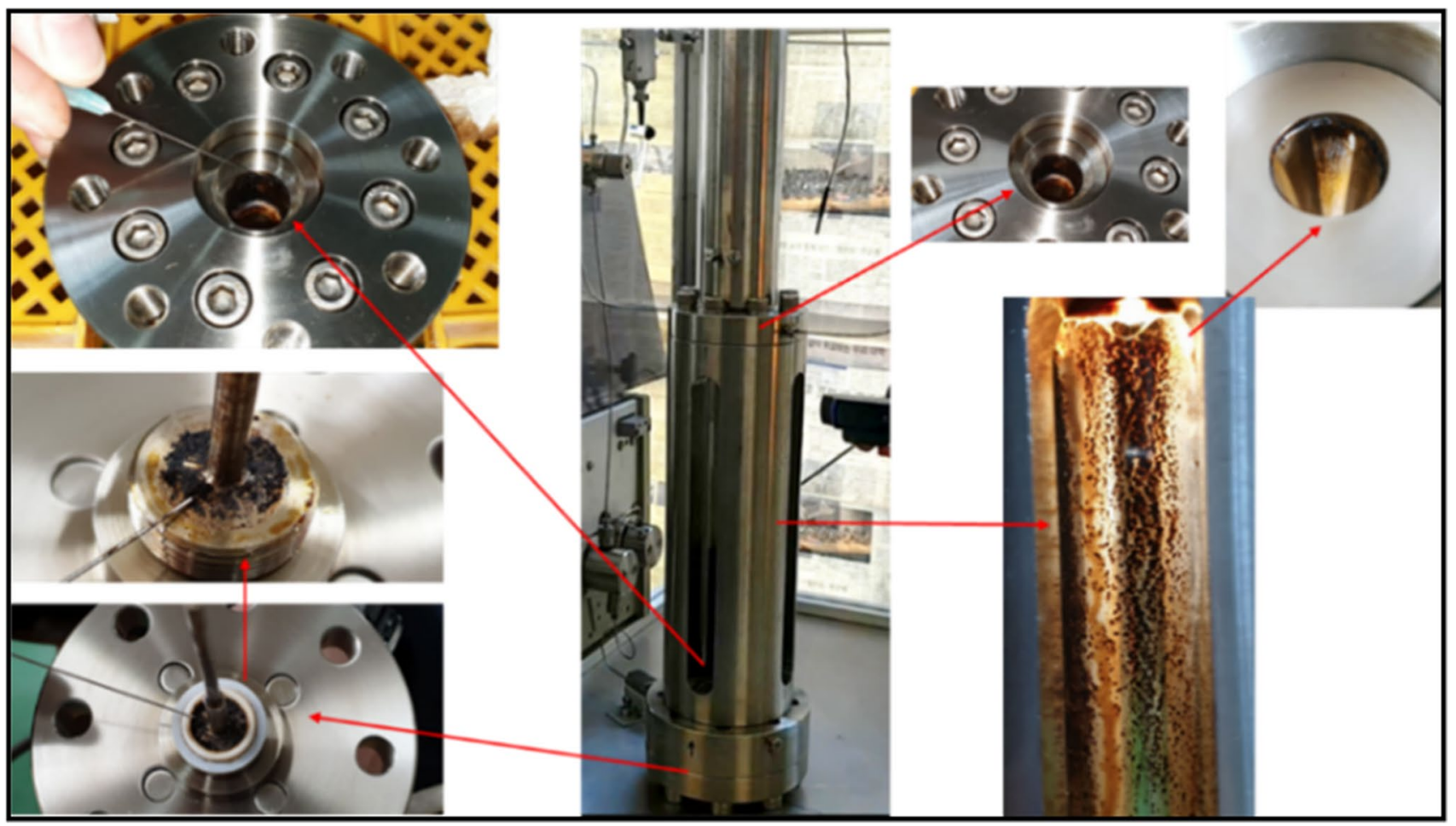

Fig. 15 Paraffin precipitation in the apparatus

Better and more consistent results are shown by Fig. 17 which shows the measurement curves at $158^{\circ} \mathrm{F}$. The curve intersection pattern and characteristics are very similar to those of Sample A1 at the same temperature shown in Fig. 11. The similarity is demonstrated by good agreement among the breakpoints of the swelling factor, viscosity, and the interfacial tension curves. At a temperature that is much higher than the pour point, the wax spots at the glass and viscosity probe are less likely to happen. This condition convinced us that $\mathrm{CO}_{2}$ injection into the reservoir containing paraffinic oil Sample B1 will be successful since the reservoir temperature is higher than $200^{\circ} \mathrm{F}$. 

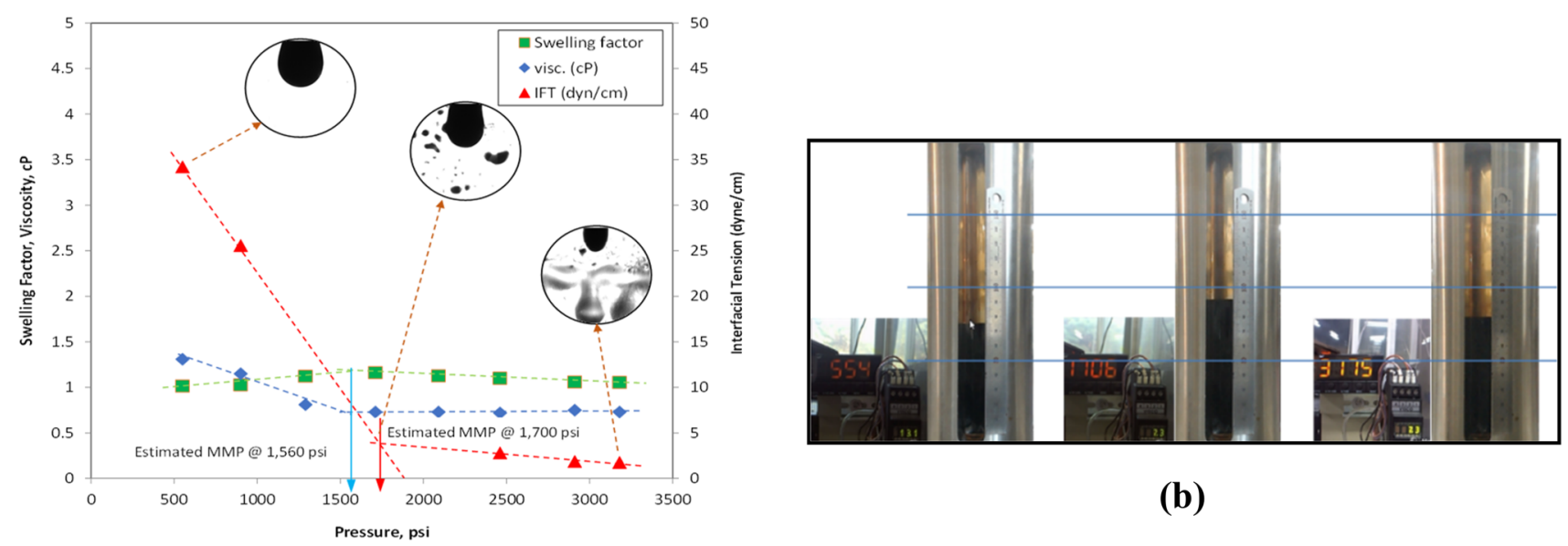

(a)

Fig. 16 Acquired data for Sample B1 at $131{ }^{\circ} \mathrm{F}$
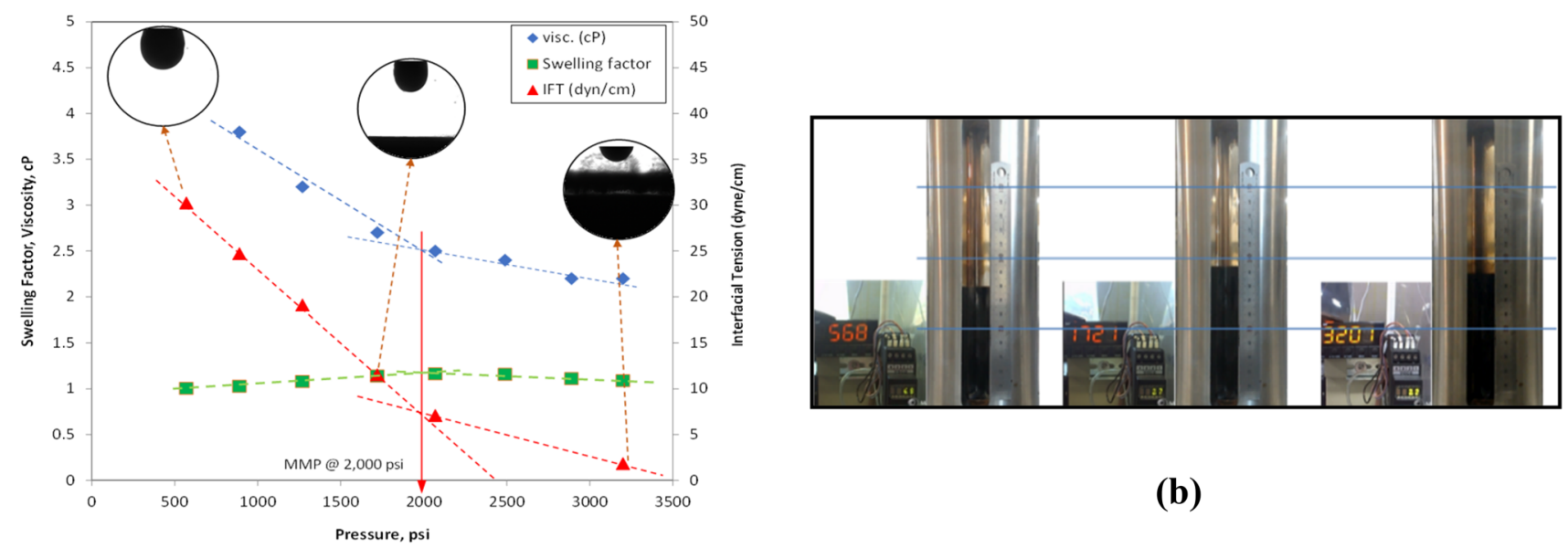

(a)

Fig. 17 Acquired data for Sample B1 at $158^{\circ} \mathrm{F}$

\section{Conclusions}

Results and discussion on the acquired data using the new apparatus draw several conclusions as follows:

1. Data acquisition using the new apparatus met the expectations of obtaining consistent data of swelling factor, interfacial tension, and viscosity.

2. The acquired data by the integrated-simultaneous measurement apparatus provided better understanding of the $\mathrm{CO}_{2}$ injection process and mechanisms. The swelling factor, interfacial tension, and viscosity have strong relationship and consistently correlated to each other.
3. Data acquisition using the apparatus has improved the understanding of previous methods of determining MMP using swelling and interfacial tension tests.

4. The simultaneous measurement of swelling factor, interfacial tension, and viscosity shows that the MMP consistently occurs at the intersection of the two-slope curves of the three parameters.

5. Extrapolating the interfacial tension curve to zero leads to higher MMP estimates. The prolonged interfacial tension measurement shows that there is a second slope confirming the MMP at zero interfacial tension is mistakenly closer to the miscible condition. 
6. Paraffin precipitation occurs and may cause blockages in reservoirs. This issue requires further investigation since the precipitation also occurs in asphaltic oils as reported previously in the literature.

7. Further applications of the new apparatus may be improved by installing a micro camera for better visual observation of miscibility process. It is also possible to connect the apparatus with a slim tube. It is expected that this improvement will enhance its capability in maintaining the consistency of experiments.

\begin{abstract}
Acknowledgments The authors would like to thank Department of Energy and Mineral Resources Engineering of Sejong University and Department of Chemical Engineering of Hongik University for facilitating the experiments. The authors also thankful to the management of Bass Oil Limited for partially funding the research.
\end{abstract}

Funding This funding was provided by Bass Oil Limited.

\section{Declarations}

Conflict of interest On behalf of all the co-authors, the corresponding author wishes to confirm that there are no known conflicts of interest associated with this publication and there has been no significant financial support for this work that could have influenced its outcome.

Open Access This article is licensed under a Creative Commons Attribution 4.0 International License, which permits use, sharing, adaptation, distribution and reproduction in any medium or format, as long as you give appropriate credit to the original author(s) and the source, provide a link to the Creative Commons licence, and indicate if changes were made. The images or other third party material in this article are included in the article's Creative Commons licence, unless indicated otherwise in a credit line to the material. If material is not included in the article's Creative Commons licence and your intended use is not permitted by statutory regulation or exceeds the permitted use, you will need to obtain permission directly from the copyright holder. To view a copy of this licence, visit http://creativecommons.org/licenses/by/4.0/.

\section{References}

Abdurrahman M, Permadi AK, Bae WS (2015) An improved method for estimating minimum miscibility pressure through condensationextraction process under swelling tests. J Petrol Sci Eng 131:165171. https://doi.org/10.1016/j.petrol.2015.04.033

Alomair O, Malallah A, Elsharkawy A, Iqbal M (2015) Prédiction de la pression miscibilité minimum (MMP) du $\mathrm{CO}_{2}$ en utilisant un algorithme basé sur l'ACE (Alternating Conditional Expectation). Oil Gas Sci Technol 70(6):967-982. https://doi.org/10.2516/ogst/ 2012097

Alston RB, Kokolis GP, James CF (1985) $\mathrm{CO}_{2}$ minimum miscibility pressure: a correlation for impure $\mathrm{CO}_{2}$ streams and live oil systems. Soc Petrol Eng J 25(2):268-274. https://doi.org/10.2118/11959-PA

Christiansen RL, Haines HK (1987) Rapid measurement of minimum miscibility pressure with the rising-bubble apparatus. SPE Reserv Eng 2(4):523-527. https://doi.org/10.2118/13114-PA

Ekundayo JM, Ghedan SG (2013) Minimum miscibility pressure measurement with slim tube apparatus-How unique is the value? SPE reservoir characterization and simulation conference and exhibition,
16-18 September, Abu Dhabi, UAE. https://doi.org/10.2118/ 165966-ms

Emera MK, Sarma HK (2006) A genetic algorithm-based model to predict $\mathrm{CO}_{2}$-Oil physical properties for dead and live oil. Canadian international petroleum conference. Calgary, Alberta, 13-15 June. https://doi.org/10.2118/2006-197

Enick RM, Holder GD, Morsi BI (1989) A thermodynamic correlation for the minimum miscibility pressure in $\mathrm{CO}_{2}$ flooding of petroleum reservoirs. SPE Reserv Eng 3(1):81-92. https://doi.org/10.2118/ 14518-pa

Flock DL, Nouar A (1984) Parametric analysis on the determination of the minimum miscibility pressure in slim tube displacements. J Can Pet Technol 23(5):80-88. https://doi.org/10.2118/84-05-12

Glaso OS (1985) Generalized minimum miscibility pressure correlation. Soc Petrol Eng J 25(6):927-934

Hand JL, Pinczewski WV (1990) Interpretation of swelling/extraction tests. SPE Reserv Eng 5(4):595-600. https://doi.org/10.2118/ 19471-PA

Holm LW (1987) Evolution of the carbon dioxide flooding processes. J Petrol Technol 39(11):1337-1342. https://doi.org/10.2118/ 17134-PA

Metcalfe RS (1982) Effects of impurities on minimum miscibility pressures and minimum enrichment levels for $\mathrm{CO}_{2}$ and rich-gas displacements. Soc Petrol Eng J 22(2):219-225. https://doi.org/10. 2118/9230-PA

Mungan N (1981) Carbon dioxide flooding-fundamentals. J Can Pet Technol 20(1):87-92. https://doi.org/10.1007/978-94-009-6140-1_5

Orr FM, Jensen CM (1984) Interpretation of pressure-composition phase diagrams for $\mathrm{CO}_{2}$ /crude-oil systems. Soc Petrol Eng J 24(5):485497. https://doi.org/10.2118/11125-PA

Orr FM, Silva MK (1987) Effect of oil composition on minimum miscibility pressure - part 2: correlation. SPE Reserv Eng 2(4):479-491. https://doi.org/10.2118/14150-PA

Rao DN (1997) A new technique of vanishing interfacial tension for miscibility determination. Fluid Phase Equilib 139(1997):311-324

Rosman A, Zana E (1977) Experimental studies of low IFT displacement by $\mathrm{CO}_{2}$ injection. SPE annual technical conference and exhibition, Denver, CO, 9-12 October. https://doi.org/10.2523/6723-ms

Stalkup FI (1978) Carbon dioxide miscible flooding: past, present, and outlook for the future. J Petrol Technol 30(8):1102-1112. https:// doi.org/10.2118/7042-PA

Stalkup FI, Lo LL, Dean RH (1990) Sensitivity to gridding of miscible flood predictions made with upstream differenced simulators. SPE/ DOE enhanced oil recovery symposium, Tulsa, OK, 22-25 April. https://doi.org/10.2523/20178-ms

Stalkup FI (1987) Displacement behavior of the condensing/vaporizing gas drive process. SPE annual technical conference and exhibition, Dallas, TX, 27-30 September

Sugiharjo, Purnomo H (2009) Perubahan Sifat-sifat Fluida reservoir Pada Injeksi $\mathrm{CO}_{2}$. Lembaran Publikasi Lemigas vol. 43. No. 1, April

Tsau JS, Bui LH, Willhite GP (2010) Swelling/extraction test of a small sample size for phase behavior study. SPE symposium on improved oil recovery, Tulsa, OK, 24-28 April. https://doi.org/10.2523/ 129728-ms

Wang Y, Peck DG (2000) Analytical calculation of minimum miscibility pressure: comprehensive testing and its application in a quantitative analysis of the effect of numerical dispersion for different miscibility development mechanisms. SPE/DOE Improved oil recovery symposium, Tulsa, OK, 3-5 April. https://doi.org/10.2118/59378-ms

Yellig WF, Metcalfe RS (1980) Determination and prediction of $\mathrm{CO}_{2}$ minimum miscibility pressures. J Petrol Technol 32(01):160-168. https://doi.org/10.2118/7477-pa

Yuan H, Johns RT, Egwuenu AM, Dindoruk B (2004) Improved MMP correlations for $\mathrm{CO}_{2}$ floods using analytical gas flooding theory. SPE symposium on improved oil recovery, Tulsa, OK, 17-21 April 
Zhang PY, Huang S, Sayegh S, Zhou XL (2004) Effect of $\mathrm{CO}_{2}$ impurities on gas-injection EOR processes. SPE symposium on improved oil recovery, Tulsa, OK, 17-21 April. https://doi.org/10.2523/89477-ms

Zick AA (1986) Combined condensing/vaporizing mechanism in the displacement of oil by enriched gases. SPE annual technical conference and exhibition, New Orleans, LA, 5-8 October. https://doi.org/10. 2523/15493-ms
Publisher's Note Springer Nature remains neutral with regard to jurisdictional claims in published maps and institutional affiliations. 